\title{
Psychoactive drug use and falls among community-dwelling Turkish older people
}

\author{
(1) Mehmet Ilkin Naharci, ${ }^{1}$ (i) Ekin Oktay Oguz, ${ }^{1}$ (i) Fatih Celebi, ${ }^{1}$ (i) Senay Ozgun Oguz, ${ }^{2}$ \\ D Osman Yilmaz, ${ }^{1}$ (D) Ilker Tasci \\ ${ }^{1}$ Department of Geriatrics, University of Health Sciences, Gulhane Training and Research Hospital, Ankara, Turkey \\ ${ }^{2}$ Department of Home Health Services, Gulhane Training and Research Hospital, Ankara, Turkey \\ ${ }^{3}$ Department of Internal Medicine, University of Health Sciences, Gulhane Training and Research Hospital, Ankara, Turkey
}

\begin{abstract}
OBJECTIVE: Data on the relationship between fall and psychoactive drug use among Turkish older people are limited. This study aims to investigate the prevalence of falls and the associations between psychoactive drug use and falls in communitydwelling Turkish older people.

METHODS: This single center study was performed using the medical records of subjects aged over 65 years admitted to the geriatric care unit. Demographic and lifestyle factors, clinical characteristics, medications, and data on mood, cognitive status, and functional performance were obtained from the comprehensive geriatric assessment records. Based on a fall history in the last 12 months, subjects were grouped as fallers and non-fallers. Subjects treated with a psychoactive drug were identified.
\end{abstract}

RESULTS: Among the total of 429 subjects, there were 184 (42.9\%) fallers and 245 (57.1\%) non-fallers. Of those, 33.3\% were on psychoactive drug treatment. The proportion of psychoactive drug users was higher in the fallers group compared to non-fallers ( $45.1 \%$ vs. $24.5 \%, \mathrm{p}<0.001)$. Multivariable logistic regression analysis showed age $\geq 75$ years $(\mathrm{OR}=1.83 ; \mathrm{CI}$ : 1.09-3.09; $\mathrm{p}=0.023)$, female gender $(\mathrm{OR}=2.70 ; \mathrm{CI}: 1.6-4.50 ; \mathrm{p}<0.001)$, and psychoactive drug use $(\mathrm{OR}=2.14 ; \mathrm{CI}: 1.32-$ 3.48; $p=0.002$ ) as independent predictors of falls.

CONCLUSION: We found that about one-third of geriatric outpatients were on psychoactive drug treatment in Turkey that was independently associated with the risk of falls.

Keywords: Aged; falls; psychoactive drugs.

Cite this article as: Naharci MI, Oguz EO, Celebi F, Ozgun Oguz S, Yilmaz O, Tasci I. Psychoactive drug use and falls among communitydwelling Turkish older people. North Clin Istanb 2020;7(3):260-266.

$F_{\mathrm{r} d}^{\mathrm{a}}$ alls are a significant common problem in older adults, reducing function and quality of life, increasing the risk for fear of falling syndrome, and causing morbidity and mortality. One-third of community-dwelling people aged over 65 years fall one or more times each year and repeated falls occur in half of them [1]. Brain trauma, hip fractures, hospitalization and death are worst outcomes of falls. Accidents are the seventh cause of deaths in older people and the majority are associated with falls [2]. Most falls arise from one or more combination risk factors, including advanced age, impaired cognitive function, comorbidities, sensory factors and environmental hazards.

Drugs are another major modifiable risk factor for falls. Of those, psychoactive drugs are the most common cause associated with falls, with sedation, impaired balance, and coordination that result in gait problems. Psychoac- 
tive drugs can be defined broadly as drugs that cross the blood-brain barrier and effects on the central nervous system. The susceptibility to drug related adverse outcomes increases due to the pharmacodynamic changes with age and up to $20 \%$ of all drug-related hospitalizations in older people is related to them [3]. These drugs are frequently used in older people to treat anxiety, sleep disorders, and neuropsychiatric symptoms of dementia $[4,5]$. However, psychoactive drug use is associated with a $50-70 \%$ increased risk of falls among older people [6]. A recent meta-analysis has shown a relationship between falls and all classes of psychoactive drugs, including antidepressants, neuroleptics, anxiolytics and hypnotics [7]. Furthermore, the risk of falls increases with higher dosage and longer duration of psychoactive drug use, which is more likely in the first weeks after the initiation of treatment [8].

In the literature, there are many studies about the relationships between psychoactive drug use and falls in community-dwelling older people [6-13]; however, this relationship has not been examined enough in outpatients in Turkey. Older outpatients with severe health problems, multi-morbidities, and complicated diseases are at high risk of fall. Therefore, psychoactive drug use may need to be more carefully evaluated by health care providers. Identifying falls and risk factors for falls is an essential issue in the medical care management for those people.

In this study, we aimed to investigate the prevalence of falls, the relationships between psychoactive drug use and falls, and clinical and demographic characteristics in community-dwelling Turkish older people.

\section{MATERIALS AND METHODS}

We used the data from the Geriatric Outpatient Clinic of the University of Health Sciences which are linked with a tertiary referral care hospital and also provides a consultant service for inpatients and home care patients. This database includes anonymous patient identifiers, demographic factors, chronic diseases, geriatric syndromes, screening tests for cognition, function, mood, and nutrition, laboratory results and currently used drugs which were obtained during the comprehensive geriatric assessment of an interdisciplinary medical team led by a geriatrician. The local ethics committee approved this study.

Exclusion criteria were the history of dementia, presence of delirium determined by the confusion assess- ment method [14], being terminally ill, bedridden or in a wheelchair, inability to stand or walk without help, and patients with incomplete data.

\section{Fall Screening}

Subjects in this study were questioned whether they had a history of one or more falls (an unplanned trip to the floor) in the last 12 months. Additionally, the number of falls, fall-related injuries and fractures were also recorded. Then, subjects were grouped into people with a history of fall (fallers) and those without a history of fall (non-fallers).

\section{Demographics and Clinical Characteristics}

Demographics were questioned for each subject of the following components: gender, age $(65-74$ and $75+$ years) and education ( $\leq 8$ years and $\geq 9$ years). Weight and height of the participants were measured using a standard scale in light clothing. The body mass index (BMI) was calculated as $\mathrm{kg} / \mathrm{m}^{2}$ and subdivided into two groups: $<30.0$ and $\geq 30.0$.

Comorbidities, including hypertension, diabetes mellitus, ischemic heart disease, chronic obstructive pulmonary disease, osteoporosis, and insomnia and the use of relevant drugs, were identified. Men with hemoglobin $<13.0 \mathrm{~g} / \mathrm{dL}$ and women with $<12.0 \mathrm{~g} /$ were diagnosed with anemia. Renal function was assessed by the Cockcroft-Gault equation corrected for gender which estimates glomerular filtration rate (GFR). A GFR $<60.0$ $\mathrm{mL} / \mathrm{min}$ was categorized as chronic renal failure.

Active medications were noted for each subject. Psychoactive drugs with sedative activity (antidepressants, anxiolytics, and antipsychotics) were screened. The classes of antidepressants recorded were the selective serotonin reuptake inhibitors (SSRIs), serotonin-norepinephrine reuptake inhibitors (SNRIs), tricyclic antidepressants (TCAs), and atypical antidepressants. Using two or more different psychoactive drugs concomitantly was defined as combination treatment. Polypharmacy was defined as $\geq 5$ drugs.

\section{Geriatric Assessment}

Mental status was assessed by the Mini-Mental State Examination (MMSE) and a lower MMSE score was defined as $\leq 24$ [15]. Nutritional status was assessed by the Mini Nutritional Assessment (MNA) and scores $\leq 11$ was defined as malnutrition [16]. Presence of de- 
pressive symptoms was evaluated by the Geriatric depression scale short form (GDS-15) and scores $>5$ was defined as depression [17]. Fall risk was assessed by the Tinetti Performance-Oriented.

Mobility Assessment (Tinetti-POMA) and scores $\leq 18$ indicated higher risk of fall [18].

The associations between categorical variables were tested using the chi-square test. The relationship of the variables on falls was evaluated by calculating odds ratios in univariate analyses. Variables for which unadjusted $\mathrm{p}$ value was $\leq 0.05$ in univariate logistic regression analysis and variables with previously demonstrated associations with increased risk of falls in older adults were identified as potential predictors and were included in the full multivariate model. The model was reduced using a backward elimination method regarding likelihood ratio test results. A p-value of less than 0.05 was accepted as statistically significant. Statistical analyses were performed using SPSS software version 24.0 (SPSS Inc, Chicago, II).

\section{RESULTS}

A total of 504 older adults who attended ambulatory visits for geriatric care in two consecutive years were evaluated. After the exclusion of 75 subjects based on the criteria defined above, the final analyses were performed with 429 individuals [280 women (65.3\%) and 149 men (34.7\%); mean age: $75.2 \pm 6.6$ years; mean BMI: $\left.30.4 \pm 5.2, \mathrm{~kg} / \mathrm{m}^{2}\right]$. Table 1 shows the demographic and clinical characteristics of the total sample and fallers and non-fallers separately.

A history of falls in the preceding 12 months was present in $184(42.9 \%)$ in subjects. Fallers were older $(p=0.004)$ and mostly female $(p<0.001)$ when compared to non-fallers. They also had higher rate of polypharmacy $(p=0.017)$, psychoactive drug use $(p<0.0001)$, insomnia $(p=0.020)$, chronic renal failure $(p=0.006)$ and fall risk based on the Tinetti-POMA score $(p=0.003)$. Psychoactive drug use was $33.3 \%$ and more common in fallers than in non-fallers ( $45.1 \%$ vs. $24.5 \%)$ (Table 1$)$. The prevalence of antidepressants use was higher in fallers than non-fallers group ( $29.9 \%$ vs. $20.8 \%)$, especially SSRIs $(23.4 \%$ vs. $13.5 \%)$. The combination treatment was more common in fallers than in non-fallers $(10.9 \%$ vs. $3.3 \%$ ) (Table 2 ).

There was no difference between fallers and nonfallers concerning increased BMI, lower education, hypertension, diabetes mellitus, ischemic heart disease, chronic obstructive pulmonary disease, osteoporosis, and anemia. The frequencies of an increased GDS score, decreased MMSE score, and decreased MNA scores were also similar in the two groups (Table 1). Of the subjects with Tinetti-POMA score $\leq 18,60.9 \%(n=28)$ had a history of falls.

Univariate and Multivariate Associations of the Study Parameters with Falls

Age $\geq 75$ years $(O R=1.772 ; C I: 1.204-2.608 ; p=0.004)$, female gender $(\mathrm{OR}=2.176 ; \mathrm{CI} \div 1.431-3.309 ; \mathrm{p}<0.0001)$, polypharmacy $(\mathrm{OR}=1.642 ; \mathrm{CI}: 1.090-2.473 ; \mathrm{p}=0.018)$, psychoactive drug use $(\mathrm{OR}=2.534 ; \mathrm{CI}: 1.680-3.823$; $\mathrm{p}<0.0001)$, insomnia $(\mathrm{OR}=1.923 ; \mathrm{CI}$ : 1.099-3.365; $\mathrm{p}=0.022)$, and $\mathrm{GFR}<60.0 \mathrm{~mL} / \mathrm{min}(\mathrm{OR}=0.567$; $\mathrm{CI}$; $0.379-0.848 ; \mathrm{p}=0.006)$ showed univariate associations with the risk of falls. Other variables showed no statistical significance in the univariate tests (Table 3).

In the multivariate regression analysis, age $\geq 75$ years $(\mathrm{OR}=1.831 ; \mathrm{CI}: 1.086-3.088 ; \mathrm{p}=0.023)$, female gender $(\mathrm{OR}=2.704 ; \mathrm{CI}: 1.626-4.496 ; \mathrm{p}<0.0001)$, and psychoactive drug use $(\mathrm{OR}=2.143$; CI: 1.320-3.478; $\mathrm{p}=0.002)$ were the independent predictors for falls in the preceding year. Polypharmacy, GDS-15 score $>5$, insomnia, anemia, and GFR $<60.0 \mathrm{~mL} / \mathrm{min}$ did not show any statistical significance in the multivariate model (Table 3 ).

\section{DISCUSSION}

This study showed and provided additional evidence linking psychoactive drug use to falls in a convenience sample of Turkish older adults when we eliminated confounding factors. A significant proportion of the whole group had a history of falls in the last year slightly more than in previous studies which may arise from the high rate of psychoactive drug use (33.3\%). Furthermore, falls were more frequent in the age group 75 years and older. Finally, women reported more falls than men.

Our study implied that the risk of developing fall was increased in community-dwelling older adults receiving psychoactive drugs, which is in line with findings from earlier cohort studies $[9,11,13]$. A retrospective cohort study of 73690 community-dwelling veterans found that patient on one or more psychoactive drug or increased dosage of that were observed to have a significantly increased fall risk [12]. Using data of German Health Interview and Examination Survey for Adults 2008-2011, an epidemiological study found that self-reported psy- 


\begin{tabular}{|c|c|c|c|c|c|c|c|}
\hline \multirow[t]{2}{*}{ Variables } & \multicolumn{2}{|c|}{$\begin{array}{c}\text { Total } \\
(n=429)\end{array}$} & \multicolumn{2}{|c|}{$\begin{array}{l}\text { Non-fallers } \\
(n=245)\end{array}$} & \multicolumn{2}{|c|}{$\begin{array}{l}\text { Fallers } \\
(n=184)\end{array}$} & \multirow[t]{2}{*}{$\mathrm{p}$} \\
\hline & $\mathrm{n}$ & $\%$ & $\mathrm{n}$ & $\%$ & $\mathrm{n}$ & $\%$ & \\
\hline \multicolumn{8}{|l|}{ Demographics } \\
\hline \multicolumn{8}{|c|}{ Age categories (years) } \\
\hline $65-74$ & 219 & 51.0 & 140 & 57.1 & 79 & 42.9 & 0.004 \\
\hline $75+$ & 210 & 49.0 & 105 & 42.9 & 105 & 57.1 & \\
\hline \multicolumn{8}{|l|}{ Gender } \\
\hline Female & 280 & 65.3 & 142 & 58.0 & 138 & 75.0 & $<0.0001$ \\
\hline \multicolumn{8}{|l|}{ BMI $\left(\mathrm{kg} / \mathrm{m}^{2}\right)$} \\
\hline$\geq 30.0$ & 189 & 46.9 & 108 & 46.2 & 81 & 47.9 & 0.725 \\
\hline \multicolumn{8}{|l|}{ Education } \\
\hline$\leq 8$ years & 282 & 65.7 & 153 & 62.4 & 129 & 70.1 & 0.098 \\
\hline \multicolumn{8}{|l|}{ Polypharmacy } \\
\hline No. (\%) yes & 207 & 53.9 & 106 & 48.6 & 101 & 60.8 & 0.017 \\
\hline \multicolumn{8}{|l|}{ Comorbidities } \\
\hline \multicolumn{8}{|l|}{ Hypertension } \\
\hline No. (\%) yes & 245 & 57.1 & 143 & 58.4 & 102 & 55.4 & 0.544 \\
\hline \multicolumn{8}{|l|}{ Diabetes mellitus } \\
\hline No. (\%) yes & 112 & 26.1 & 67 & 27.3 & 45 & 24.5 & 0.500 \\
\hline \multicolumn{8}{|c|}{ Ischemic heart disease } \\
\hline No. (\%) yes & 34 & 7.9 & 21 & 8.6 & 13 & 7.1 & 0.568 \\
\hline \multicolumn{8}{|l|}{ COPD } \\
\hline No. (\%) yes & 30 & 7.0 & 21 & 8.6 & 9 & 4.9 & 0.139 \\
\hline \multicolumn{8}{|l|}{ Osteoporosis } \\
\hline No. (\%) yes & 128 & 29.8 & 66 & 26.9 & 62 & 33.7 & 0.130 \\
\hline \multicolumn{8}{|l|}{ Anemia } \\
\hline No. (\%) yes & 78 & 18.3 & 37 & 15.3 & 41 & 22.3 & 0.064 \\
\hline \multicolumn{8}{|c|}{ GFR $<60.0 \mathrm{~mL} / \mathrm{min}$} \\
\hline No. (\%) yes & 168 & 41.7 & 84 & 35.9 & 84 & 49.7 & 0.006 \\
\hline \multicolumn{8}{|l|}{ Psychoactive drug } \\
\hline No. (\%) yes & 143 & 33.3 & 60 & 24.5 & 83 & 45.1 & $<0.0001$ \\
\hline \multicolumn{8}{|l|}{ Insomnia } \\
\hline No. (\%) yes & 58 & 13.5 & 25 & 10.2 & 33 & 17.9 & 0.020 \\
\hline \multicolumn{8}{|l|}{ GDS-15 score $>5$} \\
\hline No. (\%) yes & 136 & 33.7 & 71 & 30.5 & 65 & 38.2 & 0.104 \\
\hline \multicolumn{8}{|c|}{ Tinetti-POMA score $\leq 18$} \\
\hline No. (\%) yes & 46 & 13.3 & 18 & 8.8 & 28 & 20.0 & 0.003 \\
\hline \multicolumn{8}{|l|}{ MMSE score $\leq 24$} \\
\hline No. (\%) yes & 70 & 17.3 & 41 & 17.5 & 29 & 17.0 & 0.882 \\
\hline \multicolumn{8}{|l|}{ MNA score $\leq 11$} \\
\hline No. (\%) yes & 117 & 29.2 & 61 & 26.4 & 56 & 32.9 & 0.155 \\
\hline
\end{tabular}

BMI: Body mass index; COPD: Chronic obstructive pulmonary disease; GFR: Glomerular filtration rate; GDS: Geriatric depression scale; POMA: Performance-oriented mobility assessment; MMSE: Mini-mental state examination; MNA: Mini-nutritional assessment.

Missing values: BMI (26), polypharmacy (45), anemia (3), GFR (26), GDS-15 score (25), Tinetti-POMA score (83), MMSE score (24), and MNA score (28). 
TABLE2. Frequencies of the psychoactive drugs used by subjects for both groups

\begin{tabular}{lcc} 
Drugs & Fallers $\mathrm{n}=\mathbf{1 8 4}$ & Non-fallers $\mathrm{n}=\mathbf{2 4 5}$ \\
\hline Antidepressants & & \\
$\quad$ Total & 29.9 & 20.8 \\
SSRI & 23.4 & 13.5 \\
SNRI & 1.6 & 2.5 \\
TCA & 1.6 & 2.5 \\
Atypical & 3.3 & 2.5 \\
Anxiolytics & 1.6 & 0.0 \\
Antipsychotics & 2.7 & 0.4 \\
Combination treatment & 10.9 & 3.3 \\
\hline
\end{tabular}

SSRI: Selective serotonin reuptake inhibitor; SNRI: Serotonin-norepinephrine reuptake inhibitor; TCA: Tricyclic antidepressants. Combination treatment means using two or more different psychoactive drugs at the same time.

choactive drugs were overall associated with $64 \%$ increase in the risk of falls and recurrent falls on self-report in the past 12 months in community-dwelling older adults aged 65-79 years [10]. A prospective cohort of 1759 community-dwelling healthy older adults followed up for 12 months by telephone showed a $90 \%$ higher fall risk among psychoactive drug users [9]. Our study demonstrated a $114 \%$ increased risk of falls in a similar sample, which is considerably higher than those found in previous community-based studies $[11,13]$. Such a difference may be linked to the fact that because our outpatient clinic serves as a referral geriatric unit and most attendees have therefore increased number of comorbidities. Moreover, as a tertiary clinic, a fall history is evaluated carefully by a trained staff not to miss any fallers. Because, a significant proportion of older adults fail to recall falls and fall-related injuries that occurred in past 12 months [19].

Our study showed that among all psychoactive drugs, SSRIs and combination treatment was more frequently associated with fall, which is in line with other studies. Tinetti et al. [1] found sedative use is associated with a 28.2-fold increase in falls among older adults living in the community. Du et al. [10] reported a 6.22-fold increase in the risk of developing falls among community-dwelling older people receiving a SSRI. According to findings of Health $\mathrm{ABC}$ prospective longitudinal study with 2948 older participants, SSRI use was related to falls, with the risk varying from 1.47 to 1.62 [11]. Although the exact mechanism is still unclear, SSRIs and other psychoactive drugs may promote balance and gait problems resulting in falls through several mechanisms, including anticholinergic and extrapyramidal adverse effects, sedation, orthostatic hypotension, dizziness, and sleep disturbance [20-22].

Stopping psychoactive drugs is the most effective intervention among individuals at high fall risk; however, this could not always be possible. The patients or family's request to restart the treatment appears to be the biggest obstacle to the intervention to stop the adverse effects of these medications. This problem implies some new questions. Could the patient-centered approaches, especially those involving family education, be helpful in patients who use these drugs? Do non-pharmacological approaches have both psychological and physical clinical benefits? If these initiatives are revealed to be beneficial, individually-tailored multifactorial interventions may help to stop those drugs.

TABLE 3. Associations between variables and a history of fall based on univariate and multivariate logistic regression analysis

\begin{tabular}{lccccccc} 
& & Unadjusted OR & $95 \%$ CI & $p$ & Adjusted OR & $95 \%$ CI & p \\
\hline Age & $\geq 75$ years & $\mathbf{1 . 7 7 2}$ & $1.204-2.608$ & $\mathbf{0 . 0 0 4}$ & $\mathbf{1 . 8 3 1}$ & $1.086-3.088$ & $\mathbf{0 . 0 2 3}$ \\
Gender & Female & $\mathbf{2 . 1 7 6}$ & $1.431-3.309$ & $<\mathbf{0 . 0 0 0 1}$ & $\mathbf{2 . 7 0 4}$ & $1.626-4.496$ & $<\mathbf{0 . 0 0 0 1}$ \\
Polypharmacy & Yes & $\mathbf{1 . 6 4 2}$ & $1.090-2.473$ & $\mathbf{0 . 0 1 8}$ & 1.198 & $0.752-1.907$ & 0.447 \\
Psychoactive drug & Yes & $\mathbf{2 . 5 3 4}$ & $1.680-3.823$ & $<\mathbf{0 . 0 0 0 1}$ & $\mathbf{2 . 1 4 3}$ & $1.320-3.478$ & $\mathbf{0 . 0 0 2}$ \\
GDS-15 score $>5$ & Yes & 1.412 & $0.931-2.142$ & 0.104 & 1.087 & $0.673-1.755$ & 0.735 \\
Insomnia & Yes & $\mathbf{1 . 9 2 3}$ & $1.099-3.365$ & $\mathbf{0 . 0 2 2}$ & 1.727 & $0.905-3.296$ & 0.098 \\
Anemia & Yes & 1.589 & $0.970-2.601$ & 0.066 & 1.495 & $0.819-2.730$ & 0.190 \\
GFR $<60 \mathrm{~mL} / \mathrm{min}$ & Yes & $\mathbf{0 . 5 6 7}$ & $0.379-0.848$ & $\mathbf{0 . 0 0 6}$ & 0.801 & $0.480-1.337$ & 0.395 \\
\hline
\end{tabular}

OR: Odd ratios; CI: Confidence interval; GDS: Geriatric depression scale; GFR: Glomerular filtration rate. 
Data from the 2014 Behavioral Risk Factor Surveillance System survey analyzed by the Center for Disease Control and Prevention showed that the risk of annual fall rate increases with age, from $26.7 \%$ at ages $65-74$ years, to $29.8 \%$ at ages $75-84$ years, to $36.5 \%$ at ages $\geq 85$ years [21]. According to the data from the National Health Interview Survey study with 20,752 participants, $16.4 \%$ of community-dwelling people fell in the previous year [22]. Gale et al. [23] have reported in the English Longitudinal Study of Ageing with 4,301 men and women aged 60 and over that fall prevalence rate was $28.4 \%$ in the last two years. As expected, we observed that age of 75 years or older was an independent risk factor for falls in line with previous studies [24-27]. We observed that the prevalence of falls is slightly higher than that found in previous more extensive studies. The increased number of falls in our sample was likely due to the high rate of psychoactive drug use which may be associated with clinical characteristics of subjects requring care at a specialized referral unit. Another reason may our being a center which provides specialized care on referral from primary and secondary care. Moreover, another vital cause may be that the fall assessment is a component of our comprehensive evaluation of an older adult who reports a fall or not.

Not surprisingly, we recorded more falls among women compared to men. Most cross-sectional and longitudinal studies in community-dwelling older people have revealed a higher ratio of falls in older women [24$26,28-31]$. Decreased muscle strength, increased visual field dependence and variation in gait pattern during dual-task activities in older women have been suggested to be among the causes of higher risk of falls $[32,33]$.

There are several limitations to the present study. Firstly, we can identify associations but cannot infer causality due to the cross-sectional design of our study. Second, the study sample was obtained in one geographic location; thus, our findings cannot be readily generalized to other populations. Third, the possibility of recall errors in the general elderly populations in identifying covariates cannot be neglected.

To our knowledge, our study was the first study that examined the association between psychoactive drug use and falls in community-dwelling Turkish older people followed up in a geriatric outpatient clinic of a tertiary care hospital.

In conclusion, we demonstrated a higher risk of falls in Turkish older adults using psychoactive drugs and this was an independent predictor of falls. The findings suggest the need for increasing awareness of the adverse effects of psychoactive drugs on the risk of falls among physicians and other health care providers managing older adults at all levels of care in Turkey. Additionally, further studies are required to develop interventions that improve poor clinical outcomes in older adults by reducing psychoactive drug burden, while enhancing adherence of the patients.

Falls are common in older people but never be a condition medically acceptable. Therefore, whether subjects over 65 years have fallen at least once a year should be questioned. In the evaluation, possible risk factors should be investigated by medical history, physical examination and laboratory studies and then corrected. Furthermore, combination of education programs to prevent falls, exercises of improving strength and balance, and arrangement of environmental factors should be considered.

Ethics Committee Approval: IRB of the Gulhane Training and Research Hospital, University of Health Sciences, TR, granted approval for this study (date: 16.10.2018, number: 2018/11-225).

Conflict of Interest: No conflict of interest was declared by the authors.

Financial Disclosure: The authors declared that this study has received no financial support.

Authorship Contributions: Concept - MIN, SOO; Design - MIN, SOO; Supervision - MIN, SOO; Materials - MIN, SOO; Data collection and/or processing - MIN, SOO, IT; Analysis and/or interpretation MIN, EOO, FC, OY, IT; Literature search - MIN, EOO, FC, OY, IT; Writing - MIN, EOO, FC, OY, IT; Critical review - MIN, EOO, FC, OY, IT.

\section{REFERENCES}

1. Tinetti ME, Speechley M, Ginter SF. Risk factors for falls among elderly persons living in the community. N Engl J Med 1988;319:1701-7.

2. National Center for Health Statistics (US). Health, United States, 2016: With Chartbook on Long-term Trends in Health. Hyattsville (MD): National Center for Health Statistics (US); 2017.

3. Salvi F, Marchetti A, D’Angelo F, Boemi M, Lattanzio F, Cherubini A. Adverse drug events as a cause of hospitalization in older adults. Drug Saf 2012;35 Suppl 1:29-45. [CrossRef]

4. Carrasco-Garrido P, Jiménez-García R, Astasio-Arbiza P, OrtegaMolina P, de Miguel AG. Psychotropics use in the Spanish elderly: predictors and evolution between years 1993 and 2003. Pharmacoepidemiol Drug Saf 2007;16:449-57. [CrossRef]

5. Edelstein O, Pater K, Sharma R, Albert SM. Influence of urban residence on use of psychotropic medications in Pennsylvania, USA: crosssectional comparison of older adults attending senior centers. Drugs Aging 2014;31:141-8. [CrossRef]

6. Woolcott JC, Richardson KJ, Wiens MO, Patel B, Marin J, Khan KM, et al. Meta-analysis of the impact of 9 medication classes on falls in elderly persons. Arch Intern Med 2009;169:1952-60. [CrossRef] 
7. Bloch F, Thibaud M, Dugué B, Brèque C, Rigaud AS, Kemoun G. Psychotropic drugs and falls in the elderly people: updated literature review and meta-analysis. J Aging Health 2011;23:329-46. [CrossRef]

8. Huang AR, Mallet L, Rochefort CM, Eguale T, Buckeridge DL, Tamblyn R. Medication-related falls in the elderly: causative factors and preventive strategies. Drugs Aging 2012;29:359-76. [CrossRef]

9. Bongue B, Dupré C, Beauchet O, Rossat A, Fantino B, Colvez A. A screening tool with five risk factors was developed for fall-risk prediction in community-dwelling elderly. J Clin Epidemiol 2011;64:115260. [CrossRef]

10. Du Y, Wolf IK, Knopf H. Association of psychotropic drug use with falls among older adults in Germany. Results of the German Health Interview and Examination Survey for Adults 2008-2011 (DEGS1). PLoS One 2017;12:e0182432. [CrossRef]

11. Marcum ZA, Perera S, Thorpe JM, Switzer GE, Castle NG, Strotmeyer ES, et al; Health ABC Study. Antidepressant Use and Recurrent Falls in Community-Dwelling Older Adults: Findings From the Health ABC Study. Ann Pharmacother 2016;50:525-33. [CrossRef]

12. Pratt NL, Ramsay EN, Kalisch Ellett LM, Nguyen TA, Barratt JD, Roughead EE. Association between use of multiple psychoactive medicines and hospitalization for falls: retrospective analysis of a large healthcare claim database. Drug Saf 2014;37:529-35. [CrossRef]

13. Rossat A, Fantino B, Nitenberg C, Annweiler C, Poujol L, Herrmann FR, et al. Risk factors for falling in community-dwelling older adults: which of them are associated with the recurrence of falls? J Nutr Health Aging 2010;14:787-91. [CrossRef]

14. Inouye SK, van Dyck CH, Alessi CA, Balkin S, Siegal AP, Horwitz RI. Clarifying confusion: the confusion assessment method. A new method for detection of delirium. Ann Intern Med 1990;113:941-8. [CrossRef]

15. Cockrell JR, Folstein MF. Mini-Mental State Examination (MMSE). Psychopharmacol Bull 1988;24:689-92.

16. Vellas B, Villars H, Abellan G, Soto ME, Rolland Y, Guigoz Y, et al. Overview of the MNA--Its history and challenges. J Nutr Health Aging 2006;10:456-63.

17. Sheikh JI, Yesavage JA, Brooks JO 3rd, Friedman L, Gratzinger P, Hill $\mathrm{RD}$, et al. Proposed factor structure of the Geriatric Depression Scale. Int Psychogeriatr 1991;3:23-8. [CrossRef]

18. Harada N, Chiu V, Damron-Rodriguez J, Fowler E, Siu A, Reuben DB. Screening for balance and mobility impairment in elderly individuals living in residential care facilities. Phys Ther 1995;75:462-9. [CrossRef]

19. Cummings SR, Nevitt MC, Kidd S. Forgetting falls. The limited accuracy of recall of falls in the elderly. J Am Geriatr Soc 1988;36:613-6.

20. Williams LJ, Pasco JA, Stuart AL, Jacka FN, Brennan SL, Dobbins
AG, et al. Psychiatric disorders, psychotropic medication use and falls among women: an observational study. BMC Psychiatry 2015;15:75.

21. Bergen G, Stevens MR, Burns ER. Falls and Fall Injuries Among Adults Aged $\geq 65$ Years - United States, 2014. MMWR Morb Mortal Wkly Rep 2016;65:993-8. [CrossRef]

22. Verma SK, Willetts JL, Corns HL, Marucci-Wellman HR, Lombardi DA, Courtney TK. Falls and Fall-Related Injuries among CommunityDwelling Adults in the United States. PLoS One 2016;11:e0150939.

23. Gale CR, Cooper C, Aihie Sayer A. Prevalence and risk factors for falls in older men and women: The English Longitudinal Study of Ageing. Age Ageing 2016;45:789-94. [CrossRef]

24. Cevizci S, Uluocak Ş, Aslan C, Gökulu G, Bilir O, Bakar C. Prevalence of Falls And Associated Risk Factors Among Aged Population: Community Based Cross-Sectional Study From Turkey. Cent Eur J Public Health 2015;23:233-9. [CrossRef]

25. Deandrea S, Lucenteforte E, Bravi F, Foschi R, La Vecchia C, Negri E. Risk factors for falls in community-dwelling older people: a systematic review and meta-analysis. Epidemiology 2010;21:658-8. [CrossRef]

26. Kwan MM, Close JC, Wong AK, Lord SR. Falls incidence, risk factors, and consequences in Chinese older people: a systematic review. J Am Geriatr Soc 2011;59:536-43. [CrossRef]

27. Rubenstein LZ, Josephson KR. The epidemiology of falls and syncope. Clin Geriatr Med 2002;18:141-58. [CrossRef]

28. Cox S, Roggenkamp R, Bernard S, Smith K. The epidemiology of elderly falls attended by emergency medical services in Victoria, Australia. Injury 2018;49:1712-9. [CrossRef]

29. Pengpid S, Peltzer K. Prevalence and Risk Factors Associated with Injurious Falls among Community-Dwelling Older Adults in Indonesia. Curr Gerontol Geriatr Res 2018;2018:5964305. [CrossRef]

30. Pérez-Ros P, Martínez-Arnau FM, Tarazona-Santabalbina FJ. Risk Factors and Number of Falls as Determinants of Quality of Life of Community-Dwelling Older Adults. J Geriatr Phys Ther 2019;42:6372. [CrossRef]

31. Valderrama-Hinds LM, Al Snih S, Chen NW, Rodriguez MA, Wong R. Falls in Mexican older adults aged 60 years and older. Aging Clin Exp Res 2018;30:1345-51. [CrossRef]

32. Lord SR, Sambrook PN, Gilbert C, Kelly PJ, Nguyen T, Webster IW, et al. Postural stability, falls and fractures in the elderly: results from the Dubbo Osteoporosis Epidemiology Study. Med J Aust 1994;160:6845, 688-91. [CrossRef]

33. Johansson J, Nordström A, Nordström P. Greater Fall Risk in Elderly Women Than in Men Is Associated With Increased Gait Variability During Multitasking. J Am Med Dir Assoc 2016;17:535-40. [CrossRef] 